\title{
Sperm competition leads to functional adaptations in avian testes to maximize sperm quantity and quality
}

\author{
Stefan Lüpold, Joachim Wistuba ${ }^{1}$, Oliver S Damm, James W Rivers ${ }^{2}$ and Tim R Birkhead \\ Department of Animal and Plant Sciences, University of Sheffield, Western Bank, Sheffield S10 2TN, UK, ${ }^{1}$ Institute of \\ Reproductive and Regenerative Biology, Centre of Reproductive Medicine and Andrology, University Clinics Münster, \\ Domagkstrasse 11, 48149 Münster, Germany and ${ }^{2}$ Department of Forest Ecosystems and Society, Oregon State \\ University, 214 Richardson Hall, Corvallis, Oregon 97331-5752, USA
}

Correspondence should be addressed to S Lüpold who is now at Department of Biology, Life Sciences Complex, Syracuse University, 107 College Place, Syracuse, New York 13244-1270, USA; Email: sklupold@syr.edu

\begin{abstract}
The outcome of sperm competition (i.e. competition for fertilization between ejaculates from different males) is primarily determined by the relative number and quality of rival sperm. Therefore, the testes are under strong selection to maximize both sperm number and quality, which are likely to result in trade-offs in the process of spermatogenesis (e.g. between the rate of spermatogenesis and sperm length or sperm energetics). Comparative studies have shown positive associations between the level of sperm competition and both relative testis size and the proportion of seminiferous (sperm-producing) tissue within the testes. However, it is unknown how the seminiferous tissue itself or the process of spermatogenesis might evolve in response to sperm competition. Therefore, we quantified the different germ cell types and Sertoli cells (SC) in testes to assess the efficiency of sperm production and its associations with sperm length and mating system across 10 species of New World Blackbirds (Icteridae) that show marked variation in sperm length and sperm competition level. We found that species under strong sperm competition generate more round spermatids (RS)/spermatogonium and have SC that support a greater number of germ cells, both of which are likely to increase the maximum sperm output. However, fewer of the RS appeared to elongate to mature spermatozoa in these species, which might be the result of selection for discarding spermatids with undesirable characteristics as they develop. Our results suggest that, in addition to overall size and gross morphology, testes have also evolved functional adaptations to maximize sperm quantity and quality.
\end{abstract}

Reproduction (2011) 141 595-605

\section{Introduction}

Sperm competition (i.e. competition for fertilization between ejaculates from different males; Parker 1970) is a prevalent phenomenon throughout the animal kingdom. The outcome of this competition is largely determined by the relative number and quality of rival sperm (e.g. Martin et al. 1974, Birkhead et al. 1999, Gage et al. 2004, Snook 2005). Since both sperm number and quality are regulated by spermatogenic processes, an understanding of spermatogenesis provides useful insight into adaptations of, and constraints on, testicular function and sperm production, in relation to sperm competition.

Spermatogenesis consists of the multiplication and proliferation of spermatogonial stem cells, recombination of genetic material during meiotic divisions of spermatocytes and differentiation and maturation of spermatids into testicular sperm (Sharpe 1994, Aire 2007). In amniotes, the spermatogonia (SG) are located along the outer edge of the long and convoluted seminiferous tubules, the elongating and elongated spermatids (ES) are found around the central lumen, into which the mature spermatozoa are ultimately released, and the different types of spermatocytes and spermatids are arranged sequentially along the periphery-lumen axis (Courot et al. 1970, Sharpe 1994, Aire 2007).

Across mammalian species, the number of defined germ cell associations (referred to here as spermatogenic stages) and the duration of spermatogenesis for a given germ cell line vary considerably (Russell et al. 1990, França \& Russell 1998, Wistuba et al. 2007). Xenogenic transplantation experiments have shown that the duration of spermatogenesis is conserved and controlled by the germ cell genotype (França et al. 1998, Zeng et al. 2006), even though the maturation of the testis can be accelerated when grafted into faster-developing testes (Honaramooz et al. 2004). The time it takes to produce a single spermatozoon under normal conditions ranges 
from 30 to 78 days across species (e.g. Hess \& de Franca 2008). In contrast, spermatogenesis in birds appears to be several times faster, with a duration of 11-14 days reported across the few non-passerine birds studied so far (Noirault et al. 2006). Moreover, non-passerine birds appear to produce up to four times the number of spermatozoa/gram of testis compared with mammals (Jones \& Lin 1993). These differences may result from a faster passage through, and poorer survival in, the male post-testicular ducts by avian spermatozoa compared with mammalian spermatozoa (Jones \& Lin 1993).

In mammals, organization of the germinal epithelium takes several forms depending on the species under examination. Rodents, tupaias (tree shrews), prosimians and most Old World monkeys exhibit single-staged seminiferous epithelium in which all germ cells within a given tubular cross-section are arranged in the same stage of the spermatogenic cycle. In contrast, New World monkeys and Great Apes have a multi-stage organization of spermatogenesis, with multiple stages found in each tubular cross-section (Wistuba et al. 2003, Luetjens et al. 2005). These different types of organizations are likely to be the result of different degrees of developmental synchronization coupled with the size of the germ cell clones deriving from spermatogonial stem cells (Luetjens et al. 2005, Ehmcke et al. 2006).

Compared with mammals, much less is known about the organization of the seminiferous epithelium in birds, with our knowledge based on four domestic species of non-passerine birds, the guinea fowl (Numida meleagris), domestic fowl (Gallus domesticus), Japanese quail (Corturnix japonica) and mallard (Anas platyrhynchos). Although the multi-stage organization seen in mammals has been documented in these species (Clermont 1958, Yamamoto et al. 1967, Aire et al. 1980, de Reviers 1988, Lin et al. 1990), the organization for passerine birds is currently unknown. Passerines differ markedly from non-passerine species in the morphology of their sperm and by the presence of specialized, extragonadal ducts for sperm storage (Wolfson 1954, Jamieson 2007), both of which are likely to affect the sperm production strategy. Consequently, differences may also exist in the epithelial organization.

In addition to differences in overall topography and duration of spermatogenesis, there is also speciesspecific variation in the relative frequency of germ cells due to different conversion rates between cell stages and different levels of natural cell loss (e.g. Wistuba et al. 2003, Luetjens et al. 2005, Hess \& de Franca 2008). The relative abundance of germ cell types provides a range of indices of spermatogenesis, and comparisons between species may permit inference of functional differences in the seminiferous epithelium relative to the level of sperm competition or the length of sperm produced. For example, the theoretical baseline for meiosis is the production of four haploid round spermatids (RS) from one diploid primary spermatocyte (Luetjens et al. 2005), which itself derives from a spermatogonium through a series of mitotic cell divisions (Hess \& de Franca 2008). Moreover, the expected conversion rate of RS to ES (i.e. spermiogenesis) is theoretically 1.0 because this spermatogenic step involves solely morphological differentiation and no further cell divisions (e.g. Luetjens et al. 2005). Differences in the deviation from these theoretical rates among species indicate interspecific variation in the efficiency of spermatogonial mitosis, overall rate of spermatogenesis or the magnitude of germ cell loss that normally occurs during spermatogenesis (Berndtson 1977, Wistuba et al. 2003, Segatelli et al. 2004), which might be associated with differences in the sperm production strategy between species.

Apart from germ cells, the seminiferous epithelium also contains Sertoli cells (SC) that provide structural and nutritional support to the developing germ cells (e.g. Fawcett 1975, Griswold 1993). In birds and mammals, SC do not proliferate in adult testes under normal conditions (e.g. Clermont \& Perey 1957, Nagy 1972, Bozkurt et al. 2007), although their numbers can vary seasonally or can be induced to vary (e.g. Johnson et al. 1991, Meachem et al. 2005). Overall, however, the number of SC/unit of seminiferous tissue of breeding individuals is species-specific and provides a reference for normalizing germ cell numbers in comparisons among cell numbers and different testis sizes (Gondos \& Berndtson 1993, Luetjens et al. 2005, Hess \& de Franca 2008). The support capacity (or workload) of $\mathrm{SC}$ is expressed as the total number of germ cells/SC (e.g. Wistuba et al. 2003), and their efficiency is estimated by the number of RS associated with each SC at any time (e.g. Segatelli et al. 2004). Both parameters restrict the amount of sperm produced/unit of seminiferous tissue to a species-specific limit and can be used to compare the maximum likely sperm production capacity across species (e.g. Russell \& Peterson 1984, Luetjens et al. 2005).

The sperm production capacity of testes is particularly important in the context of sperm competition theory as fertilization success is mainly determined by the relative number and quality of sperm between the ejaculates of the rival males (e.g. Martin et al. 1974, Birkhead et al. 1999, Gage et al. 2004, Snook 2005). Under high levels of sperm competition, males are predicted to produce large quantities of high-quality sperm, but various morphological and physiological constraints may limit male investment in sperm production or trade off sperm quantity against quality.

One trait that has been shown to trade off against sperm number is sperm length (e.g. Pitnick 1996, Oppliger et al. 1998, Lüpold et al. 2009c, Parker et al. 2010, Immler et al. 2011; but see Snook 2005). Several comparative studies across the animal kingdom indicate that sperm competition often favors longer sperm (e.g. Gage 1994, Balshine et al. 2001, Byrne et al. 2003, Lüpold et al. 2009b), although overall there have been 
mixed results regarding the association between sperm length and sperm competition (Snook 2005, Immler et al. 2011). Longer sperm can be advantageous if they are able to swim faster than shorter sperm (e.g. Fitzpatrick et al. 2009, Lüpold et al. 2009a), to better displace rival sperm or avoid being displaced from female sperm-storage organs (LaMunyon \& Ward 1998, Pattarini et al. 2006), or if sperm length coevolves with these female storage organs (e.g. Briskie \& Montgomerie 1992, Miller \& Pitnick 2002).

Regardless of the selection mechanism, longer sperm may require both a larger testis and more time to be produced (e.g. Pitnick 1996, Ramm \& Stockley 2010). However, for a given testis size, spatial constraints within the testes are likely to result in a trade-off between sperm length (and potentially quality) and sperm number (Pitnick 1996, Lüpold et al. 2009c).

Across passerine birds, a recent study found that species under strong sperm competition exhibit a higher proportion of seminiferous tissue in their testes relative to species with weak sperm competition (Lüpold et al. 2009c). These results suggest that species under strong sperm competition, which typically transfer more and larger ejaculates, have evolved testes capable of producing more sperm than expected from their size alone, probably due to spatial constraints within the body cavity. However, that study focused on the relative quantity of the seminiferous tissue (Lüpold et al. 2009c), and it remains unknown whether the seminiferous epithelium itself varies between species, either in its organization or in relative numbers of different germ cell types.

In the current study, we examined the variation in the relative frequency of germ cell types and SC in New World Blackbirds (Icteridae) to assess the evolutionary significance of interspecific variation in spermatogenic parameters. Species in this group vary considerably in their mating system and thus in the level of sperm competition (Jaramillo \& Burke 1999), in the size and gross morphology of their testes (Lüpold et al. 2009c), as well as in sperm length and function (Lüpold et al. $2009 a, 2009 b)$. Species with relatively large testes exhibit a disproportionate amount of seminiferous tissue, suggesting that they might produce more sperm than predicted by testis size alone (Lüpold et al. 2009c), but they also produce longer sperm (Lüpold et al. 2009b), which might decrease the rate of spermatogenesis and reduce daily sperm output. We examined the organization and cellular composition of the seminiferous epithelium and tested the hypothesis that interspecific variation in spermatogenic parameters and SC function was related to the level of sperm competition or sperm length across species. Specifically, we predicted that species under the most intense sperm competition would produce sperm more efficiently as reflected by both higher spermatogenic indices and an increased SC support capacity.

\section{Results}

\section{Composition of seminiferous epithelium}

All 10 species analyzed showed largely a consistent single-stage arrangement of the seminiferous epithelium (see Fig. 1). Thus, we did not further investigate or quantify the epithelial organization.

The intraspecific mean numbers of germ cells/gram testicular tissue ranged between 375 and $607 \times 10^{6}$ but did not differ significantly among the 10 study species $\left(N=32\right.$ males; $F_{9,22}=1.58, P=0.18$; Table 1; Fig. 2$)$. However, $39 \%$ of the total variation was explained by interspecific variation, and we cannot reject the possibility that biologically meaningful differences remained undetected due to the relatively low statistical power of our analyses. The absolute numbers of the distinct cell types/gram of testis differed significantly between species for SG $\left(F_{9,22}=2.99, P=0.02\right)$ and
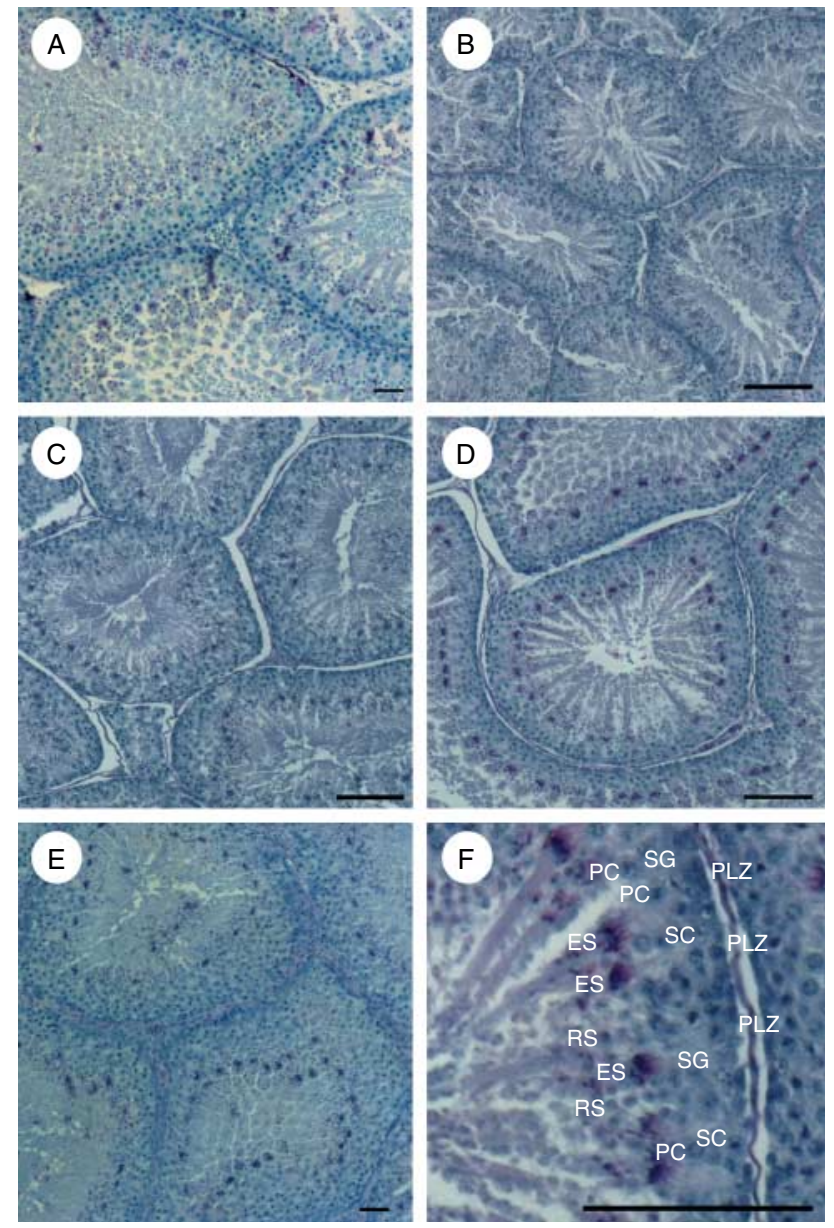

Figure 1 PAS-stained testicular histology of selected species; crosssections of seminiferous tubules. A: Agelaius phoeniceus, B: Molothrus rufoaxilliaris, C: M. bonariensis, D: Chrysomus ruficapillus, E: Sturnella neglecta, $\mathrm{F}$ : detail of $\mathrm{D}$ showing the composition of the seminiferous epithelium, with each label left of corresponding cell type (SG, spermatogonia; PLZ, preleptotene to zygotene spermatocytes; PC, pachytene spermatocytes; RS, round spermatids; ES, elongated spermatids; SC, Sertoli cells). All bars represent $100 \mu \mathrm{m}$. 


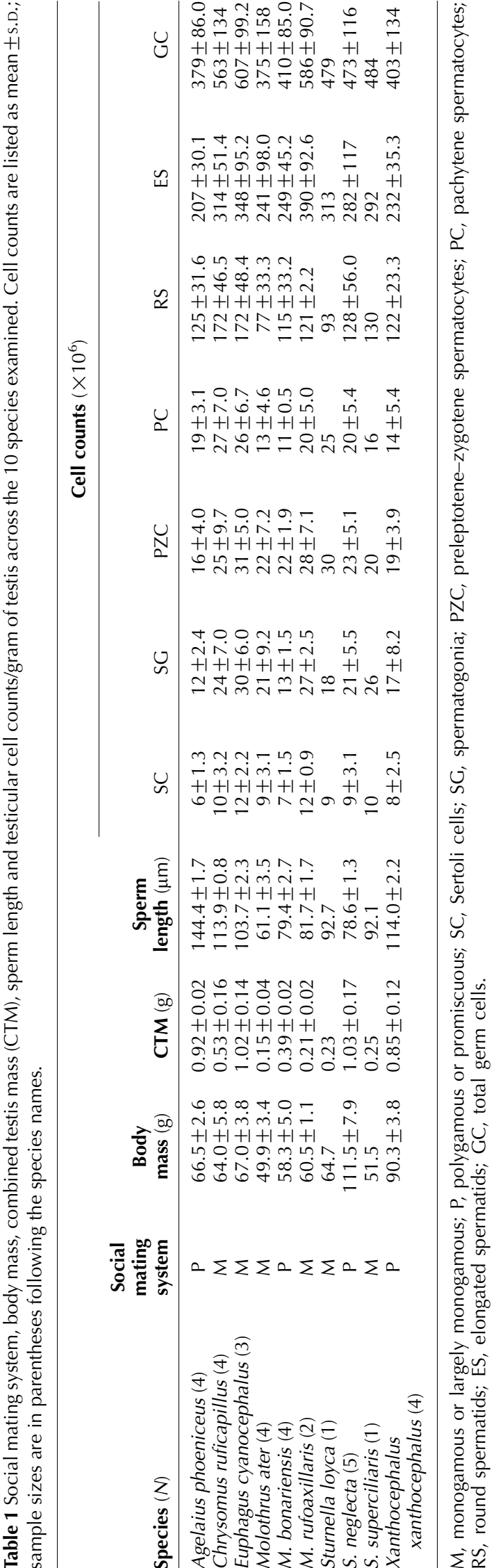

pachytene spermatocytes (PC; $F_{9,22}=4.11, P=0.003$ ), but not for the other germ cell types (preleptotenezygotene spermatocytes (PZC): $F_{9,22}=1.76, P=0.13$; RS: $F_{9,22}=1.82, P=0.12$; ES: $F_{9,22}=1.56, P=0.19$ ) or SC $\left(F_{9,22}=1.89, P=0.11\right)$. However, despite statistically non-significant results in most of these analyses, 39-63\% of the total variation was attributable to interspecific differences in each case. A restriction to the seven species with at least three males, and thus more robust cell number estimates, yielded similar results.

ES formed the highest proportion of the total number of germ cells (GC; 54.6-66.7\%), followed by the RS $(19.5-32.9 \%)$ and the two types of spermatocytes (PZC: 4.2-6.2\%; PC: $2.7-5.2 \%)$. The SG constituted the remaining $3.1-5.7 \%$ of all germ cells.

When expressing the number of germ cells/SC rather than per unit of testicular tissue, we found statistically significant differences among species for $\mathrm{PC}\left(F_{9,22}=\right.$ $3.14, P=0.01)$, RS $\left(F_{9,22}=7.27, P<0.001\right)$ and GC $\left(F_{9,22}=3.27, \quad P=0.01\right)$, with $56-75 \%$ explained by species. In contrast, no significant differences were detected for the other germ cells (SG: $F_{9,22}=1.56$, $P=0.19$; PZC: $F_{9,22}=0.52, P=0.85$; ES: $F_{9,22}=1.01$, $P=0.46$ ), although for $\mathrm{SG}$, the interspecific variation explained $39 \%$ of total variation. Again, restricting the analyses to the seven species with at least three males yielded qualitatively the same results.

\section{Associations of spermatogenic indices with relative testis size and sperm length}

All the following results are based on mean cell numbers for each species. From the absolute number of germ cells, we calculated five different spermatogenic indices (Table 2) that describe the efficiency of spermatogenic processes and SC function (e.g. Wistuba et al. 2003, Segatelli et al. 2004), and tested whether these indices were associated either with relative testis mass (i.e. combined testis mass controlled for body mass, both logtransformed) or with sperm length (also log-transformed).

The proportion of germ cells that have entered the final spermatogenic stage of spermatid elongation (ES/GC; an index of spermatogenic efficiency) decreased with both relative testis mass and sperm length (Table 3). By contrast, the number of RS relative to PC (RS/PC; an index of the efficiency of meiosis or the rate of germ cell loss during meiosis) was not significantly correlated with both relative testis mass and sperm length (Table 3), but the effect size and distribution for relative testis mass suggests that a significant, positive association might be detected with greater statistical power. The number of $\mathrm{RS} /$ spermatogonium (RS/SG), however, which provides an index of the overall rate of spermatogenic cell divisions (mitotic and meiotic), increased significantly with relative testis mass and sperm length (Table 3 and Fig. 3). Finally, we found positive associations for the SC support capacity, measured by the number of either RS or 


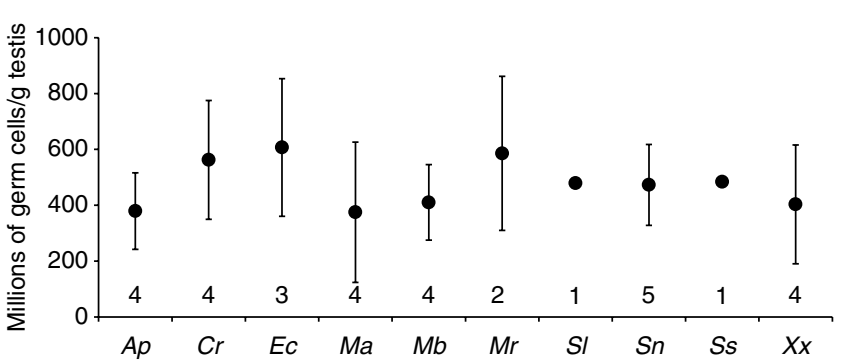

Figure 2 Number of germ cells/gram testis across the 10 study species. The error bars represent $95 \% \mathrm{Cl}$; the numbers at the bottom of the graph indicate the sample sizes. Species abbreviations: Ap, Agelaius phoeniceus; Cr, Chrysomus ruficapillus; Ec, Euphagus cyanocephalus; Ma, Molothrus ater; Mb, M. bonariensis; Mr, M. rufoaxillaris; SI, Sturnella loyca; Sn, S. neglecta; Ss, S. superciliaris; Xx, Xanthocephalus xanthocephalus.

all germ cells associated with each SC (i.e. RS/SC and GC/SC, respectively; Table 3 and Fig. 4).

To address the potential circularity caused by using relative testis mass in a study on associations between sperm competition and testicular traits, we repeated the above analyses using social mating system as an independent index of sperm competition. Although not all results were statistically significant, the magnitude and distribution of the effect sizes suggest that polygamous or promiscuous species tended to exhibit a lower ES/GC proportion (Cohen's $d(95 \%$ confidence interval $(\mathrm{Cl}))=-0.99(-2.33$ to 0.40$), t=-1.56, P=0.16)$, but higher RS/PC $(d=1.04 \quad(-0.37$ to 2.38$), t=1.61$, $P=0.15)$ and RS/SG proportions $(d=1.95$ (0.30 to $3.53), t=3.03, P=0.02)$, respectively, than species that are monogamous or largely monogamous. Similarly, polygamous species also showed an increased SC support capacity than (largely) monogamous species (RS/SC: $d=1.55$ (0.01 to 3.00), $t=2.40, P=0.04$; GC/SC: $d=1.20(-0.24$ to 2.58$), t=1.86, P=0.10)$. All these analyses were not significantly associated with phylogeny $\left(\lambda<0.0001^{1.00,<0.03}\right)$.

Finally, we examined whether the conversion ratios from one germ cell stage to the next (expressed as the ratio of daughter cells:parent cells) covaried with relative testis mass, indicating the potential effects of sperm competition on the conversion efficiency or germ cell loss at different stages of spermatogenesis. All of these associations were not significantly influenced by phylogeny (all $\lambda<0.0001^{1.00,}<0.01-0.66$ ). The number of PLZ derived from SG (SG:PLZ) was not significantly correlated with relative testis mass (testis mass partial $r=-0.08(-0.66$ to -0.59$), t=-0.20, P=0.84)$. The PC:PLZ ratio was not significantly correlated with relative testis mass but the association exhibited a relatively large effect size, such that we currently cannot reject the possibility of a real, but statistically undetected, positive association (partial $r=0.48(-0.31$ to $0.81), t=1.34, P=0.22)$, and the same applied to RS:PC (see Table 3). Finally, we found a negative relationship between the ES:RS ratio and relative testis mass (partial $r=-0.88$ ( -0.95 to -0.49$), \quad t=-4.66, P=0.002$; Fig. 5). Since the ES:RS ratio relates directly to sperm elongation, we also tested its relationship with sperm length, which was also significantly negative $(r=-0.73$ $(-0.89$ to -0.11$), t=-2.79, P=0.02)$.

\section{Discussion}

Across 10 species of Icteridae that vary markedly in their social mating system, our study revealed that variation in the composition of the seminiferous epithelium was associated with differences in sperm competition and sperm length. Most notably, our work found that each spermatogonium generates more RS in species under intense sperm competition relative to species with weaker levels of sperm competition, but relatively fewer of these spermatids elongate and mature. Additionally, the number of germ cells supported by each SC was positively associated with the level of sperm competition. Taken together, these results indicate that intense sperm competition not only selects for more and denser sperm-producing tissue in the testes but also affects various aspects of spermatogenesis itself, and that the links and trade-offs between sperm length, sperm number and sperm competition are more complex than generally assumed.

\section{Seminiferous epithelium organization and cell numbers}

The species examined in our study consistently exhibited a single-stage arrangement of the seminiferous epithelium, which contrasts with the reported multi-stage organization in the four species of non-passerine birds studied to date (Clermont 1958, Yamamoto et al. 1967, Aire et al. 1980, de Reviers 1988, Lin et al. 1990). We do not know if this is a general difference between passerine and non-passerine birds and, if so, whether it is associated with the evolution of the considerable differences in sperm phenotypes and general features

Table 2 Mean, range, and 95\% confidence interval $(\mathrm{Cl})$ of the five indices of spermatogenic and Sertoli cell function used across the 10 study species.

\begin{tabular}{|c|c|c|c|}
\hline Index & Mean & Range & $95 \% \mathrm{Cl}$ \\
\hline Elongated spermatids/total germ cells (ES/GC), i.e. spermatogenic efficiency & 0.60 & $0.55-0.64$ & $0.57-0.63$ \\
\hline Round spermatids/pachytene spermatocytes (RS/PC), i.e. meiotic index & 6.92 & $3.75-10.52$ & $5.59-8.26$ \\
\hline Round spermatids/spermatogonia (RS/SG), i.e. overall rate of spermatogenesis & 6.42 & $3.60-10.48$ & $4.90-7.94$ \\
\hline Round spermatids/Sertoli cells (RS/SC), i.e. Sertoli cell efficiency & 13.86 & $8.39-20.19$ & $11.30-16.43$ \\
\hline Total germ cells/Sertoli cells (GC/SC), i.e. Sertoli cell workload & 51.77 & $40.92-61.32$ & $47.72-55.81$ \\
\hline
\end{tabular}


Table 3 Associations of the five indices of spermatogenic and Sertoli cell function with (A) relative testis mass (i.e. combined testis mass corrected for body mass) and (B) sperm length across the 10 study species. All analyses were controlled for phylogeny, but none of the relationships were significantly associated with phylogeny (all $\lambda<0.001^{1.0},<0.001-0.10$ ). In the analyses including relative testis mass, the statistics of body mass (all partial $r=0.15-0.70$, all $P=0.05-0.88$ ) are omitted in the table for simplicity, and only the partial correlation statistics for combined testis mass are presented.

\begin{tabular}{lcc}
\hline Variables & Effect size $\boldsymbol{r}(95 \% \mathrm{Cl})$ & $\boldsymbol{t}$ \\
\hline (A) Relative testis mass & & -5.27 \\
Elongated spermatids/total germ cells (ES/GC) & $-0.91(-0.96$ to -0.57$)$ & 1.12 \\
Round spermatids/pachytene spermatocytes (RS/PC) & $0.42(-0.37$ to 0.79$)$ & 2.35 \\
Round spermatids/spermatogonia (RS/SG) & $0.69(-0.03$ to 0.88$)$ & 4.17 \\
Round spermatids/Sertoli cells (RS/SC) & $0.86(0.40$ to 0.95$)$ & 1.64 \\
Total germ cells/Sertoli cells (GC/SC) & $0.56(-0.23$ to 0.84$)$ & 0.001 \\
(B) Sperm length & & -3.36 \\
Elongated spermatids/total germ cells (ES/GC) & $-0.77(-0.91$ to -0.20$)$ & 0.42 \\
Round spermatids/pachytene spermatocytes (RS/PC) & $0.16(-0.51$ to 0.67$)$ & 2.88 \\
Round spermatids/spermatogonia (RS/SG) & $0.74(0.14$ to 0.89$)$ & 3.60 \\
Round spermatids/Sertoli cells (RS/SC) & $0.81(0.30$ to 0.92$)$ & 3.06 \\
Total germ cells/Sertoli cells (GC/SC) & $0.76(0.18$ to 0.90$)$ & 0.06 \\
\hline
\end{tabular}

of the male reproductive tract (e.g. seminal glomera as a sperm-storage organ in passerines) that are found between these two groups. It also remains unclear how the different types of organizations are related to the efficiency of sperm production. In mammals, it is assumed that the spermatogenic efficiency decreases with the asynchrony of the epithelial organization, partly because the heterogeneity resulting from mixed seminiferous tubule stages may reduce the efficiency of the SC compared with synchronized germ cell development and SC activity (e.g. Sharpe 1994, Wistuba et al. 2003). However, Wistuba et al. (2003) found no significant difference in the spermatogenic efficiency across a range of primates that vary in their epithelial arrangement, suggesting that the spermatogenic efficiency is not tightly linked to the topology of the seminiferous tissue.

Unlike the epithelial organization, we found some differences between species in the density of SC or germ cells. Additionally, the species we examined also tended to deviate somewhat in their cell densities from other vertebrates. For example, the number of SC (6-12 $\times 10^{6}$ cells/g testis) in this study was lower than in most mammalian taxa $\left(16-130 \times 10^{6}\right.$ cells/g testis; Wing \& Christensen 1982, Russell et al. 1990, França \& Godinho 2003, Wistuba et al. 2003), but an order of magnitude higher than in the domestic turkey Meleagris gallopavo (i.e. $6.5 \times 10^{3}$ cells/g testis; Noirault et al. 2006). In contrast, the total germ cell counts (375-607 $\times 10^{6}$ cells/g testis) were relatively high compared with mammals, such as primates $\left(200-350 \times 10^{6}\right.$; Wistuba et al. 2003) or the laboratory rat Rattus norvegicus $\left(150 \times 10^{6}\right.$; Wing \& Christensen 1982). Consequently, each SC in Icterids appeared to support a considerably larger number of germ cells (i.e. SC workload) than in mammals (41-61 compared with 10-35 germ cells/SC across mammals; Wing \& Christensen 1982, Wistuba et al. 2003, Segatelli et al. 2004), even though their SC efficiency (8-20 RS/SC) was similar to that of turkey (12; Noirault et al. 2006) and mammals (5-20; Luetjens et al. 2005, Hess \& de Franca 2008). Since the number of germ cells supported by a single SC limits the maximum sperm production capacity (e.g. Hess \& de Franca 2008), Icterids (and possibly passerine birds in general) may produce sperm more efficiently than mammals. This idea is also supported by a relatively large number of ES generated per given number of germ cells (ES/GC; 0.55-0.67) compared with primates $(<0.3$; Wistuba et al. 2003) and a similar index across a wider range of mammalian taxa (i.e. volumetric rather than numerical proportion of ES, also <0.3; Russell et al. 1990). If both the SC function and the spermatogenic efficiency are indeed higher in birds than in mammals, these differences provide a physiological explanation for Jones \& Lin's (1993) observation that the daily sperm production rate tends to be higher in birds than in mammals.

\section{Spermatogenesis and its associations with sperm competition and sperm length}

Among the species of Icteridae examined, the degree of sperm competition was associated with several spermatogenic parameters. For example, the proportion of germ

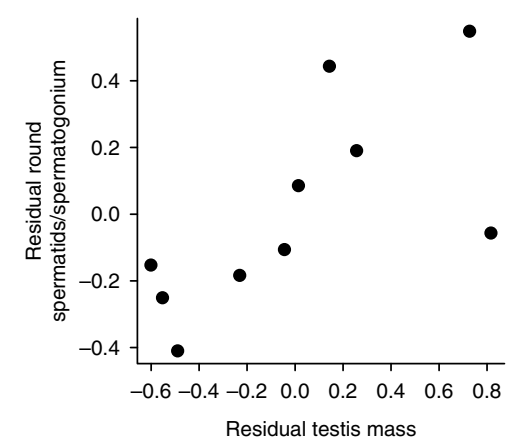

Figure 3 Partial residual plot of the interspecific association between the number of round spermatids/spermatogonium (overall rate of spermatogenesis) and testis mass (both controlled for body mass and phylogeny) across the 10 study species (partial $r=0.69, P=0.05$ ). 

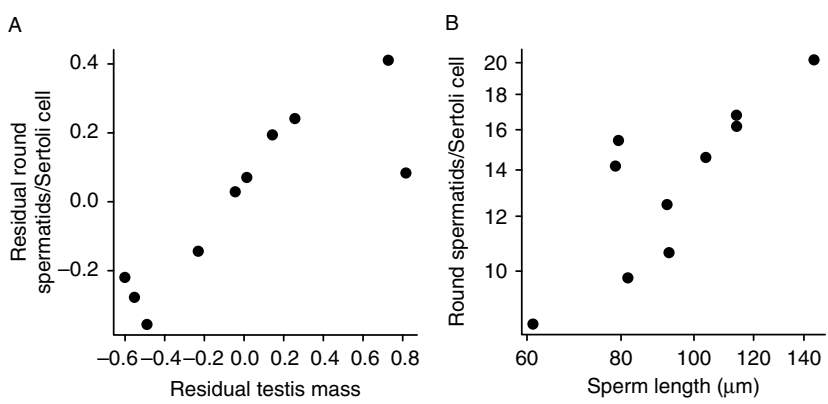

Figure 4 Interspecific relationships (A) between the residuals of the number of round spermatids/Sertoli cell (Sertoli cell efficiency) and testis mass (partial $r=0.86, P=0.004$; both axes controlled for body mass and phylogeny) and (B) between the number of round spermatids/Sertoli cell and sperm length $(r=0.81, P=0.007)$ across the 10 study species.

cells in the phase of spermatid elongation decreased with sperm competition. This result contrasts with a study of primates, where the proportion of ES was found to be independent of mating system (Wistuba et al. 2003). Furthermore, this result seems counter-intuitive as one would expect promiscuous species to have evolved more efficient sperm production (i.e. generating relatively more ES per given number of germ cells) than socially monogamous species, because of the increased sperm demands needed by intense sperm competition. However, the proportion of ES alone may not reflect a complete picture of the efficiency of sperm production; separating the spermatogenic process into cell division and spermatid elongation stages suggests more complex links between sperm competition and spermatogenic parameters.

Focusing on the cell division stage, we found polygamous Icterid species to generate relatively more RS from each spermatogonium than (largely) monogamous species. Thus, the generation of haploid cells through mitotic and meiotic cell divisions appears to become more efficient as the level of sperm competition increases, which is likely to be due to a lower apoptotic rate. Apoptosis is a natural process that eliminates germ cells with defects or DNA mutations during meiosis, and also by cell-density regulation during the spermatogonial phase to limit the germ cells to the number that can be supported by the available SC (e.g. Roosen-Rungen 1973, França \& Russell 1998, Weinbauer et al. 2001). Research that examines whether the number of apoptotic cells is indeed negatively associated with sperm across species with varying levels of competition would be especially helpful in understanding the role played by apoptosis in reducing sperm number.

Although Icterid species under high levels of sperm competition produced greater numbers of RS, they exhibited a lower conversion rate from round to ES. This pattern could be the result of two mechanisms that may work alone or together. First, species under strong sperm competition produce longer sperm (Lüpold et al. 2009b), which might increase the energetic investment in any single sperm cell and the duration of spermatid elongation and maturation (e.g. Pitnick 1996, Ramm \& Stockley 2010). In fact, the relationship between ES/RS and sperm length was negative but how this relates to the rate of spermiation or potential energetic constraints currently remains unknown. For measurements of the duration of specific spermatogenic stages, germ cells have to be labeled with compounds such as ${ }^{3} \mathrm{H}$-thymidine or 5-bromodeoxyuridine and subsequently traced through the spermatogenic cycle (e.g. Amann \& Lambiase 1969, Rosiepen et al. 1994). In addition, detailed information and precise histological definitions of different spermatogenic stages for each species are necessary to estimate the frequency of stages across a series of tubular cross-sections, and such information is currently lacking for passerine birds. Consequently, although the description and quantification of spermatogenic stages can be done, measurements of their duration are logistically challenging with wild birds as in our study. However, established captive populations of different passerine birds could help resolve the links between spermatogenic processes and sperm length, and a study of taxa that differ in the interspecific relationship between sperm length and sperm competition (e.g. Sylviidae versus Fringillidae; Immler \& Birkhead 2007) might be particularly helpful in this regard.

Secondly, species under intense selection may have a higher apoptotic rate during the post-meiotic stages of spermatogenesis. The decline in the ES:RS ratio with increasing relative testis mass suggests that relatively fewer spermatids undergo elongation as sperm competition increases. It seems plausible that species under strong sperm competition may have a more effective mechanism to filter out spermatids with undesirable characteristics as they elongate, such that relatively more cells at earlier spermatogenic stages are needed to produce a given number of high-quality sperm, thereby reducing the proportion of ES among all germ cells. To date, studies comparing the abundance of apoptotic

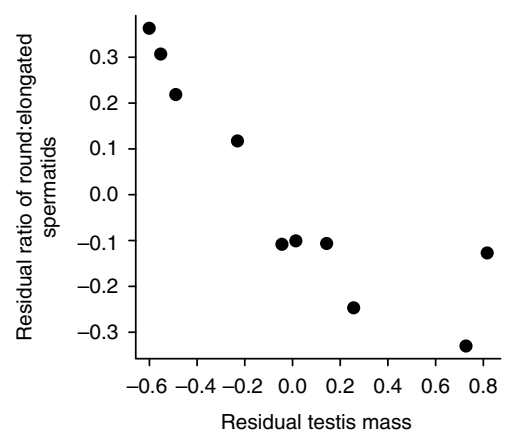

Figure 5 Partial residual plot of the interspecific relationship between the conversion ratio of elongated spermatids:round spermatids and testis mass (both controlled for body mass and phylogeny) across the 10 study species (partial $r=-0.88, P=0.002$ ). 
germ cells in the testes or the DNA integrity between species of different levels of sperm competition are lacking. However, several recent comparative studies in passerine birds, including the Icteridae, indicate that sperm morphology covaries positively with sperm performance (e.g. Lüpold et al. 2009a) and characteristics of the female reproductive tract (Briskie et al. 1997), but also that the variation in sperm morphology decreases with the level of post-copulatory sexual selection both between and within males (Calhim et al. 2007, Immler et al. 2008, Lüpold et al. 2009b; but see Kleven et al. 2008). Thus, quality control during spermatogenesis might play a more important role in species under strong sperm competition than in others, but empirical data are needed to test this idea.

It remains unclear why we found an average of 1.73.3 ES/RS, even though RS are not known to go through further cell divisions. We cannot draw any firm conclusions because detailed information on the timing and processes of spermatogenesis are lacking for passerine birds, but we suggest that spermatid elongation may take substantially longer than the stage of RS, such that relatively more elongating spermatids are found in the testis. This would be consistent with reports on the spermatogenic cycle of the domestic fowl (G. domesticus), where spermatid elongation appears to take approximately half of the entire duration of spermatogenesis (de Reviers 1988). Detailed studies on the kinetics of the spermatogenic cycle in passerine birds might shed light on this.

Although species under high levels of sperm competition exhibit a smaller number of ES relative to the earlier germ cell stages, which appears to reflect lessefficient sperm production, their testes are relatively larger and contain a disproportionate amount of seminiferous tissue (Lüpold et al. 2009c). These testes should thus nonetheless be able to generate more total sperm than species of comparable size but with relatively smaller testes. In addition, sperm production also depends strongly on the number and support capacity of the SC (França \& Russell 1998, Hess \& de Franca 2008). Across the Icteridae, species with relatively large testes and producing long sperm exhibited relatively more SC (due to proportionate increase with testis size), each of which also supported a greater number of RS or germ cells in general. Therefore, it seems likely that the daily sperm production rate is facilitated by the increased SC abundance and support capacity to a higher level than expected from testis size alone.

\section{Conclusions}

Our data add further empirical evidence to the idea that increasing testis size is only one of several adaptations that maximize sperm production under high degrees of sperm competition. Our previous study documented positive covariation between the level of sperm competition and the density of the sperm-producing tissue (Lüpold et al. 2009C), and the data in the present study indicate that such covariation also exists for the SC support capacity that sets the upper limit to sperm production. Although we have not measured the kinetics of spermatogenesis, we have found variation in the ratios between different germ cells that were associated with both sperm competition and sperm length. Based on our findings, we hypothesize that species under intense sperm competition produce more round but relatively fewer ES than other species, due to the production of longer sperm or stronger selection against poor sperm to minimize the number of low-quality sperm in each ejaculate. However, the same species have more efficient SC, which can support a larger number of germ cells simultaneously and thereby probably increase the daily sperm production rate. Overall, with the strong selection for producing large quantities of high-quality sperm, testes have evolved various adaptations at different levels, from overall size to the amount of seminiferous tissue and its function.

\section{Materials and Methods}

\section{Sample collection and histological preparation}

We opportunistically collected 32 males from 10 different species during the peak of their respective breeding season in North America and South America. Immediately after collection, testes were fixed in Bouin's fixative (Ricca Chemical Company, Arlington, TX, USA) for $24 \mathrm{~h}$ before being preserved in $70 \%$ alcohol until preparation. For each male, we measured the length, width and height of both testes to the nearest $0.1 \mathrm{~mm}$ using calipers and weighed them to the nearest $0.001 \mathrm{~g}$ using a Mettler AT261 digital balance (Mettler, Greifensee, Switzerland). The histological preparation involved dehydrating the specimens with a series of ethanol baths with increasing concentration (70, 90 and $100 \%$ respectively), embedding them in paraffin, sectioning the tissue blocks ( $20 \mu \mathrm{m}$ thick) and staining the mounted sections with periodic acid and hematoxylin (Weinbauer et al. 2001).

Using the optical dissector method (e.g. Zhengwei et al. 1997, Wistuba et al. 2003), we calculated the number of germ and SC/testis, by selecting 32 microscopic fields (141 $\times 141 \mu \mathrm{m})$ per animal for cell counts using a systematic, uniform, haphazard sampling scheme (Gundersen \& Jensen 1987). In brief, we brought the upper surface of the section into focus, ignored tissue in the first $3 \mu \mathrm{m}$ to avoid interference from surface imperfections and examined tissue in the next $15 \mu \mathrm{m}$ by counting the cells when the nuclei came sharply into focus according to the dissector principle (Sterio 1984), with a vertical distance of $5 \mu \mathrm{m}$ between levels. To avoid repeated counts of ES that were oriented vertically under the microscope (due to head lengths of up to over $15 \mu \mathrm{m}$; Lüpold et al. 2009b), we counted the heads of any given vertical spermatid bundle in only one of the four levels. We calculated the numerical density of each cell type by dividing the number of enumerated 
cells (across all frames) by the volume of all dissectors (Weinbauer et al. 2001). We counted separately the following cells: SG, PZC, PC, RS and elongating/ES, and determined the total number of germ cells (GC). In addition to germ cells, we also counted the nuclei of SC.

Following Wistuba et al. (2003) and Segatelli et al. (2004), we obtained the following five indices that describe the efficiency of spermatogenic processes and SC function: i) ES/GC (spermatogenic efficiency); ii) RS/PC (rate of germ cell loss during meiosis, meiotic index); iii) RS/SG (overall rate of spermatogenesis); iv) RS/SC (SC efficiency); and v) GC/SC (SC workload).

\section{Sperm length and sperm competition}

From each male, we also determined mean sperm length to the nearest $0.5 \mu \mathrm{m}$ from measurements of 5-10 haphazardly selected, morphologically undamaged sperm, using computerassisted image analysis at magnifications of $\times 250$ or $\times 400$ (depending on sperm length). The species of this study spanned the entire range of sperm lengths reported previously for 38 different species of Icteridae, i.e. 61-145 $\mu \mathrm{m}$ (Lüpold et al. 2009b).

As an index of sperm competition, we used relative testis mass by including log(body mass) as a covariate in our analyses with $\log$ (combined testis mass) as the explanatory variable. However, we are aware that using relative testis mass as an index of sperm competition in a study focusing on the effects of sperm competition on testicular traits can be problematic due to potential circularity in reasoning. Therefore, we obtained information on the social mating systems from the literature (Webster 1992, Jaramillo \& Burke 1999) and classified the species into two categories: (M) monogamous or largely monogamous and $(\mathrm{P})$ polygamous or promiscuous (see Lüpold et al. 2009c). Although the social mating system is a fairly crude measure of sperm competition (e.g. extra-pair paternity is not considered), it provides independent estimates of sperm competition risk compared with relative testis mass.

\section{Statistical analyses}

We conducted statistical analyses using the statistical package R v.2.11.1 (R Foundation for Statistical Computing 2010) and transformed non-normal data distributions appropriately to meet the parametric requirements of the statistical models (see below).

To control for phylogenetic effects, we used a subset of a phylogenetic tree that was constructed based on cytochrome- $b$ and NADH dehydrogenase subunit 2 sequences (for details see Lüpold et al. 2009b). We then accounted for statistical nonindependence of data points by shared ancestry of species (Felsenstein 1985, Harvey \& Pagel 1991) using a generalized least-squares (GLS) approach in a phylogenetic framework (Pagel 1999, Freckleton et al. 2002). This approach allows the estimation of the phylogenetic scaling parameter $\lambda$, with values of $\lambda$ close to 0 corresponding to traits where the similarities are likely to have evolved independently of phylogeny, and $\lambda$ close to 1 indicating a complete phylogenetic association of the traits. We used likelihood ratio tests to compare models including the maximum likelihood value of $\lambda$ with models where $\lambda$ was set to 0 or 1 , respectively. Superscripts following the $\lambda$ estimates denote significance levels of these likelihood ratio tests (first superscript: against $\lambda=0$; second superscript: against $\lambda=1)$. We report these results together with the effect size (i.e. (partial) correlation coefficient $r$ or Cohen's $d$, respectively) and $95 \% \mathrm{Cls}$ that we calculated from the $t$-values of the GLS models (Nakagawa \& Cuthill 2007), which were controlled for phylogeny and, in the case of relative testis mass, represent partial $r$ of combined testis mass after controlling for body mass.

\section{Declaration of interest}

The authors declare that there is no conflict of interest that could be perceived as prejudicing the impartiality of the research reported.

\section{Funding}

S Lüpold was supported by the Swiss National Science Foundation (Grant No. PBSK33-114636) and a Sheffield University Overseas Research Student Award, J Wistuba by the Deutsche Forschungsgemeinschaft (Grant No. WE 1167/4$1 /-2$ ) and T R Birkhead by the Leverhulme Trust.

\section{Acknowledgements}

We are most grateful for the field assistance and technical help of D Ortiz, C Ruiz and F Ruiz. Furthermore, the authors are indebted to J Salzig and $\mathrm{H}$ Kersebom as well as to J Ehmcke and S Schlatt at the Centre of Reproductive Medicine and Andrology for technical assistance, support and fruitful discussions.

\section{References}

Aire TA 2007 Spermatogenesis and testicular cycles. In Reproductive Biology and Phylogeny of Birds, pp 279-347. Ed. BGM Jamieson. Enfield, New Hampshire: Science Publishers.

Aire TA, Olowo-Okorun MO \& Ayeni JS 1980 The seminiferous epithelium in the guinea fowl (Numida meleagris). Cell and Tissue Research 205 319-325. (doi:10.1007/BF00234690)

Amann RP \& Lambiase JT Jr 1969 The male rabbit. III. Determination of daily sperm production by means of testicular homogenates. Journal of Animal Science 28 369-374.

Balshine S, Leach BJ, Neat F, Werner NY \& Montgomerie R 2001 Sperm size of African cichlids in relation to sperm competition. Behavioral Ecology 12 726-731. (doi:10.1093/beheco/12.6.726)

Berndtson WE 1977 Methods for quantifying mammalian spermatogenesis: a review. Journal of Animal Science 44 818-833.

Birkhead TR, Martínez JG, Burke T \& Froman DP 1999 Sperm mobility determines the outcome of sperm competition in the domestic fowl. Proceedings of the Royal Society of London. Series B 266 1759-1764. (doi:10.1098/rspb.1999.0843)

Bozkurt HH, Aktaş A, Ulkay MB \& Firat UB 2007 Sertoli cell proliferation during the post hatching period in domestic fowl. Journal of Veterinary Science 8 219-222. (doi:10.4142/jvs.2007.8.3.219)

Briskie JV \& Montgomerie R 1992 Sperm size and sperm competition in birds. Proceedings of the Royal Society of London. Series B 247 89-95. (doi:10.1098/rspb.1992.0013) 
Briskie JV, Montgomerie R \& Birkhead TR 1997 The evolution of sperm size in birds. Evolution 51 937-945. (doi:10.2307/2411167)

Byrne PG, Simmons LW \& Roberts JD 2003 Sperm competition and the evolution of gamete morphology in frogs. Proceedings of the Royal Society of London. Series B 270 2079-2086. (doi:10.1098/rspb.2003. 2433)

Calhim S, Immler S \& Birkhead TR 2007 Postcopulatory sexual selection is associated with reduced variation in sperm morphology. PLOS ONE 2 e413 (doi: 410.1371/journal.pone.0000413). (doi:10.1371/journal. pone.0000413)

Clermont Y 1958 Structure de l'épithélium séminal et mode de renouvellement des spermatogonies chez le canard. Archives d'Anatomie Microscopique et de Morphologie Expérimentale 44 47-66.

Clermont Y \& Perey B 1957 Quantitative study of the cell population of the seminiferous tubules in immature rats. American Journal of Anatomy $\mathbf{1 0 0}$ 241-267. (doi:10.1002/aja.1001000205)

Courot M, Hochereau-de Reviers M-T \& Ortavant R 1970 Spermatogenesis. In The Testis, pp 339-432. Eds AD Johnson, WR Gomes \& NL Vandemark. New York: Academic Press.

Ehmcke J, Wistuba J \& Schlatt S 2006 Spermatogonia: physiology, pathology and clinical relevance. Human Reproduction Update 12 275-282. (doi:10.1093/humupd/dmk001)

Fawcett DW 1975 Ultrastructure and function of the Sertoli cell. In Handbook of Physiology, pp 21-55. Eds DW Hamilton \& RO Greep. Washington, DC: American Physiological Society.

Felsenstein J 1985 Phylogenies and the comparative method. American Naturalist 125 1-15. (doi:10.1086/284325)

Fitzpatrick JL, Montgomerie R, Desjardins JK, Stiver KA, Kolm N \& Balshine S 2009 Female promiscuity promotes the evolution of faster sperm in cichlid fishes. PNAS 106 1128-1132. (doi:10.1073/pnas. 0809990106)

França LR \& Godinho CL 2003 Testis morphometry, seminiferous epithelium cycle length, and daily sperm production in domestic cats (Felis catus). Biology of Reproduction 68 1554-1561. (doi:10.1095/ biolreprod.102.010652)

França LR \& Russell LD 1998 The testis of domestic animals. In Male Reproduction. A Multidisciplinary Overview, pp 197-219. Eds F Martínez \& J Regadera. Madrid: Churchill Livingsone.

França LR, Ogawa T, Avarbockm MR, Brinster RL \& Russell LD 1998 Germ cell genotype control cell cycle during spermatogenesis in the rat. Biology of Reproduction 59 1371-1377. (doi:10.1095/biolreprod59.6. 1371)

Freckleton RP, Harvey PH \& Pagel M 2002 Phylogenetic analysis and comparative data: a test and review of evidence. American Naturalist 160 712-726. (doi:10.1086/343873)

Gage MJG 1994 Associations between body size, mating pattern, testis size and sperm lengths across butterflies. Proceedings of the Royal Society of London. Series B 258 247-254. (doi:10.1098/rspb.1994.0169)

Gage MJG, Macfarlane CP, Yeates S, Ward RG, Searle JB \& Parker GA 2004 Spermatozoal traits and sperm competition in Atlantic salmon: relative sperm velocity is the primary determinant of fertilization success. Current Biology 14 44-47. (doi:10.1016/j.cub.2003.12.028)

Gondos B \& Berndtson WE 1993 Postnatal and pubertal development of Sertoli cells. In The Sertoli Cell, pp 115-154. Eds LD Russell \& MD Griswold. Clearwater, FL: Cache River Press.

Griswold MD 1993 Protein secretion by Sertoli cells. In The Sertoli Cell, pp 195-200. Eds LD Russell \& MD Griswold. Clearwater, FL: Cache River Press.

Gundersen HJ \& Jensen EB 1987 The efficiency of systematic sampling in stereology and its prediction. Journal of Microscopy 147 229-263.

Harvey PH \& Pagel MD 1991 The Comparative Method in Evolutionary Biology, Oxford, UK: Oxford University Press.

Hess RA \& de Franca LR 2008 Spermatogenesis and cycle of the seminiferous epithelium. In Molecular Mechanisms in Spermatogenesis, pp 1-15. Ed. CY Cheng. New York: Springer.

Honaramooz A, Li M-W, Penedo MCT, Meyers S \& Dobrinski I 2004 Accelerated maturation of primate testis by xenografting into mice. Biology of Reproduction 70 1500-1503. (doi:10.1095/biolreprod.103. 025536)

Immler S \& Birkhead TR 2007 Sperm competition and sperm midpiece size: no consistent pattern in passerine birds. Proceedings of the Royal Society of London. Series B 274 561-568. (doi:10.1098/rspb.2006.3752)
Immler S, Calhim S \& Birkhead TR 2008 Increased postcopulatory sexual selection reduces the intramale variation in sperm design. Evolution 62 1538-1543. (doi:10.1111/j.1558-5646.2008.00393.x)

Immler S, Pitnick S, Parker GA, Durrant K, Lüpold S, Calhim S \& Birkhead TR 2011 Resolving variation in the reproductive tradeoff between sperm size and number. PNAS 108 5325-5330. (doi:10.1073/ pnas.1009059108)

Jamieson BGM 2007 Avian spermatozoa: structure and phylogeny. In Reproductive Biology and Phylogeny of Birds, pp 349-511. Ed. BGM Jamieson. Enfield, New Hampshire: Science Publishers.

Jaramillo A \& Burke P 1999 New World Blackbirds: the Icterids, London: Helm.

Johnson L, Varner DD, Tatum ME \& Scrutchfield WL 1991 Season but not age affects Sertoli cell number in adult stallions. Biology of Reproduction 45 404-410. (doi:10.1095/biolreprod45.3.404)

Jones RC \& Lin M 1993 Spermatogenesis in birds. Oxford Reviews of Reproductive Biology 15 233-264.

Kleven O, Laskemoen T, Fossøy F, Robertson RJ \& Lifjeld JT 2008 Intraspecific variation in sperm length is negatively related to sperm competition in passerine birds. Evolution 62 494-499. (doi:10.1111/j. 1558-5646.2007.00287.x)

LaMunyon CW \& Ward S 1998 Larger sperm outcompete smaller sperm in the nematode Caenorhabditis elegans. Proceedings of the Royal Society of London. Series B 265 1997-2000. (doi:10.1098/rspb.1998. 0531)

Lin M, Jones RC \& Blackshaw AW 1990 The cycle of the seminiferous epithelium in the Japanese quail (Coturnix coturnix japonica) and estimation of its duration. Journal of Reproduction and Fertility $\mathbf{8 8}$ 481-490. (doi:10.1530/jrf.0.0880481)

Luetjens CM, Weinbauer GF \& Wistuba J 2005 Primate spermatogenesis: new insights into comparative testicular organisation, spermatogenic efficiency and endocrine control. Biological Reviews 80 475-488. (doi:10.1017/S1464793105006755)

Lüpold S, Calhim S, Immler S \& Birkhead TR 2009a Sperm morphology and sperm velocity in passerine birds. Proceedings of the Royal Society of London. Series B 276 1175-1181. (doi:10.1098/rspb.2008.1645)

Lüpold S, Linz GM \& Birkhead TR 2009b Sperm design and variation in the New World Blackbirds (Icteridae). Behavioral Ecology and Sociobiology 63 899-909. (doi:10.1007/s00265-009-0733-6)

Lüpold S, Linz GM, Rivers JW, Westneat DF \& Birkhead TR 2009C Sperm competition selects beyond relative testes size in birds. Evolution 63 391-402. (doi:10.1111/j.1558-5646.2008.00571.x)

Martin PA, Reimers TJ, Lodge JR \& Dziuk PJ 1974 Effect of ratios and numbers of spermatozoa mixed from two males on proportions of offspring. Journal of Reproduction and Fertility 39 251-258. (doi:10. 1530/jrf.0.0390251)

Meachem SJ, Stanton PG \& Schlatt S 2005 Follicle-stimulating hormone regulates both Sertoli cell and spermatogonial populations in the adult photoinhibited Djungarian hamster testis. Biology of Reproduction $\mathbf{7 2}$ 1187-1193. (doi:10.1095/biolreprod.104.039321)

Miller GT \& Pitnick S 2002 Sperm-female coevolution in Drosophila. Science 298 1230-1233. (doi:10.1126/science.1076968)

Nagy F 1972 Cell division kinetics and DNA synthesis in the immature Sertoli cells of the rat testis. Journal of Reproduction and Fertility $\mathbf{3 8}$ 389-395. (doi:10.1530/jrf.0.0280389)

Nakagawa S \& Cuthill IC 2007 Effect size, confidence interval and statistical significance: a practical guide for biologists. Biological Reviews $\mathbf{8 2}$ 591-605. (doi:10.1111/j.1469-185X.2007.00027.x)

Noirault J, Brillard JP \& Bakst MR 2006 Spermatogenesis in the turkey (Meleagris gallopavo): quantitative approach in immature and adult males subjected to various photoperiods. Theriogenology 65 845-859. (doi:10.1016/j.theriogenology.2005.01.012)

Oppliger A, Hosken DJ \& Ribi G 1998 Snail sperm production characteristics vary with sperm competition risk. Proceedings of the Royal Society of London. Series B 265 1527-1534. (doi:10.1098/rspb. 1998.0468)

Pagel M 1999 Inferring the historical patterns of biological evolution. Nature 401 877-884. (doi:10.1038/44766)

Parker GA 1970 Sperm competition and its evolutionary consequences in the insects. Biological Reviews 45 526-567. (doi:10.1111/j.1469-185X. 1970.tb01176.x) 
Parker GA, Immler S, Pitnick S \& Birkhead TR 2010 Sperm competition games: sperm size (mass) and number under raffle and displacement, and the evolution of $P_{2}$. Journal of Theoretical Biology 264 1003-1023. (doi:10.1016/j.jtbi.2010.03.003)

Pattarini JM, Starmer WT, Bjork A \& Pitnick S 2006 Mechanisms underlying the sperm quality advantage in Drosophila melanogaster. Evolution 60 2064-2080. (doi:10.1554/06-142.1)

Pitnick S 1996 Investment in testes and the cost of making long sperm in Drosophila. American Naturalist 148 57-80. (doi:10.1086/285911)

Ramm SA \& Stockley P 2010 Sperm competition and sperm length influence the rate of mammalian spermatogenesis. Biology Letters $\mathbf{6}$ 219-221. (doi:10.1098/rsbl.2009.0635)

de Reviers M 1988 Appareil génital mâle et production des spermatozoïdes. In Reproduction des Volailles et Production d'Oeufs, pp 141-181. Ed. B Sauveur. Paris: INRA.

Roosen-Rungen EC 1973 Germinal-cell loss in normal metazoan spermatogenesis. Journal of Reproduction and Fertility 35 339-348. (doi:10. 1530/jrf.0.0350339)

Rosiepen G, Weinbauer GF, Schlatt S, Behre HM \& Nieschlag E 1994 Duration of the cycle of the seminiferous epithelium, estimated by the 5-bromodeoxyuridine technique, in laboratory and feral rats. Journal of Reproduction and Fertility 100 299-306. (doi:10.1530/jrf.0.1000299)

Russell LD \& Peterson RN 1984 Determination of the elongate spermatid Sertoli cell ratio in various mammals. Journal of Reproduction and Fertility 70 635-641. (doi:10.1530/jrf.0.0700635)

Russell LD, Ren HP, Hikim IS, Schulze W \& Hikim APS 1990 A comparative study in twelve mammalian species of volume densities, volumes, and numerical densities of selected testis components, emphasizing those related to the Sertoli cell. American Journal of Anatomy 188 21-30. (doi:10.1002/aja.1001880104)

Segatelli TM, França LR, Pinheiro PFF, Almeida CCD, Martinez M \& Martinez FE 2004 Spermatogenic cycle length and spermatogenic efficiency in the gerbil (Meriones unguiculatus). Journal of Andrology 25 872-880.

Sharpe RM 1994 Regulation of spermatogenesis. In The Physiology of Reproduction, pp 1363-1394. Eds E Knobil \& JD Neill. New York: Raven Press.

Snook RR 2005 Sperm in competition: not playing by the numbers. Trends in Ecology \& Evolution 20 46-53. (doi:10.1016/j.tree.2004.10.011)
Sterio DC 1984 The unbiased estimation of number and sizes of arbitrary particles using the dissector. Journal of Microscopy 134 127-136.

Webster MS 1992 Sexual dimorphism, mating system and body size in New World Blackbirds (Icterinae). Evolution 46 1621-1641. (doi:10.2307/ 2410020)

Weinbauer GF, Aslam H, Krishnamurty H, Brinkworth MH, Einspanier A \& Hodges JK 2001 Quantitative analysis of spermatogenesis and apoptosis in the common Marmoset (Callithrix jacchus) reveals high rates of spermatogonial turnover and high spermatogenic efficiency. Biology of Reproduction 64 120-126. (doi:10.1095/biolreprod64.1.120)

Wing TY \& Christensen AK 1982 Morphometric studies on rat seminiferous tubules. American Journal of Anatomy 165 13-25. (doi:10.1002/aja. 1001650103)

Wistuba J, Schrod A, Greve B, Hodges JK, Aslam H, Weinbauer GF \& Luetjens CM 2003 Organization of seminiferous epithelium in primates: relationship to spermatogenic efficiency, phylogeny, and mating system. Biology of Reproduction 69 582-591. (doi:10.1095/biolreprod.103. 015925)

Wistuba J, Stuckenborg JB \& Luetjens CM 2007 Mammalian spermatogenesis. Functional Development and Embryology 1 99-117.

Wolfson A 1954 Sperm storage at lower-than-body temperature outside the body cavity in some passerine birds. Science 120 68-71. (doi:10.1126/ science.120.3106.68)

Yamamoto S, Tamate H \& Itikawa O 1967 Morphological studies on the sexual maturation in the male Japanese quail (Coturnix coturnix japonica). II. The germ cell types and cellular associations during spermatogenesis. Tohoku Journal of Agricultural Research 18 27-37.

Zeng W, Avelar GF, Rathi R, França LR \& Dobrinski I 2006 The length of the spermatogenic cycle is conserved in porcine and ovine testis xenografts. Journal of Andrology 27 527-533. (doi:10.2164/jandrol.05143)

Zhengwei Y, McLachlan RI, Bremner WJ \& Wredford NG 1997 Quantitative (stereological) study of normal spermatogenesis in the adult monkey (Macaca fascicularis). Journal of Andrology 18 681-687.

Received 3 December 2010

First decision 23 December 2010

Accepted 9 February 2011 